Short Note

\title{
Globalization, Inequality, Say's Law, and Fiscal Globalism
}

\author{
Gerasimos T. Soldatos \\ Department of Economics, Westminster Tashkent, Tashkent 10047, Uzbekistan; soldgera@yahoo.com; \\ Tel./Fax: +73-4524-55369
}

Received: 30 May 2017; Accepted: 7 July 2017; Published: 10 July 2017

\begin{abstract}
This is a brief note maintaining that financial globalization has been faster than the integration of the remaining sectors of the world economy, thus encouraging wealth inequality, under-production, and under-consumption in line with Say's Law. Financial investment has become more profitable than real investment, discouraging production ventures, and weakening labor's relative income position and purchasing power. Moreover, this article works out a model of international government indirect tax competition as a policy means against increasing inequality. The mentality under which this tax policy paradigm is put forward is that the competition of nation states in a fiscal globalism fashion crystallizes the optimal level of centralization under globalism; optimal, that is, from the viewpoint of safeguarding against the manipulation of world markets by financiers.
\end{abstract}

Keywords: globalization; wealth inequality; Say's law; fiscal globalism

\section{Introduction}

A recent article in The Economist [1] reports the grave consequences the rising wealth inequality within and between countries may have worldwide if the economics professions and policymakers do not manage to address this problem properly. It is noted that manmade ways that have brought down this problem whenever it emerged in the past were mass warfare, genuine revolution, and state collapse. Based on a dynamic wealth accumulation model, Pikkety and Saez [2] suggest that wealth inequality starts rising when the after-tax rate of return on capital or the capitalization of past wealth exceeds the growth rate of the economy. They caution against the confusion between (personal) income and wealth (factor income) inequality as the former may become high, but still be generally less extreme than the latter. Their conclusion is that "there are powerful forces pushing alternately in the direction of rising or shrinking inequality. Which one dominates depends on the institutions and policies that societies choose to adopt" (pp. 842-843).

The present article (i) singles out rapid financial globalization as the driving force behind inequality-cum-under-consumption and under-production, and (ii) examines the role that national tax policies can play to at least halt the increasing inequality. The next section clarifies the thesis of Stiglitz [3] on the nexus between inequality and under-consumption. It next combines this with Minsky's [4] work to put forward the view that this development is the result of financial globalization. The pro-financial sector bias of globalization is also responsible for under-production. The overall picture of the current ailing state of the national and world economy is one that verifies Say's law, specifically from this under-production-cum-under-consumption point of view. Section 3 reviews briefly the policy arsenal against these consequences of globalization with the emphasis on policy measures of international perspective. Since modern globalization and increasing inequality are supposed to be positively correlated, Section 4 works out a model of "fiscal globalism" in support of this article's thesis that national governments can be vehicles of policymaking against increasing inequality. Section 5 concludes this article with comments, clarifying further the theses discussed herein. 


\section{Inequality and Under-Consumption, Globalization, and Under-Production, in Reference to Say's Law}

Under-consumption is a term signifying an excess supply in the goods market. It is accompanied by excess saving which should be matched at equilibrium by excess investment demand, leading next to a period of a lower volume of output, unemployment, and wage reduction. This is how the term was coined originally by Sismondi [5], who saw over-production as the result of maldistribution of income, while Hobson [6] noted in addition that domestic capital finds a way out of under-consumption by setting up "imperialist" business abroad. Nevertheless, the case of under-consumption appears to be verified nowadays in reverse causality. The thesis of this article is that the financial and neo-imperialist character of modern (as opposed mainly to the gold standard) globalization [7] is responsible for under-production and for Stiglitz-like income inequality. Additionally, the reduced buying power of labor coming out of this inequality matches under-production, as in Say's law. Stigltz emphasizes the increasing wealth inequality across countries-hurting especially the poor ones-which in turn is attributed to the institutional background of current globalization. It is a background which is also being held responsible for within-country inequalities, under-consumption, and recessionary trends in general. Stiglitz relates this background to the institutional developments of the modern economy in the financial sector as they have been exploited by the employer at the workplace.

He notes that inequality and economic instability are positively correlated because of the following chain of events. Given the development of the financial system, the rich prefer to sustain the consumer demand of their products by reducing wages and lending to their workers. For example, instead of paying a wage of $\$ 100$, the rich employer pays $\$ 70$ and lends the remaining $\$ 30$. However, the debt clears slowly, it piles up, the original growth rate cannot be sustained, borrowing stops, under-consumption sets in, and eventually the economy collapses. The income diverted to the rich does not increase their consumption as much as would be required to compensate for the reduced consumption of the workers. Krugman [8] objects to this point. He argues that this kind of under-consumption presumes that increasing inequality increases the saving rate of the rich which, he documents, is not the case. Yet, the essence of Stiglitz's point is that if, for instance, 10 workers spend $\$ 1000$ and one rich man spends another $\$ 1000$ and saves $\$ 500$, then increasing inequality makes workers spend say $\$ 800$, while the rich man spend $\$ 1150$ and save $\$ 550$. Total consumption has declined by $\$ 50$ and the saving rate of the rich has also declined from $500 / 1500=0.33$ to $550 / 1700=0.32$.

Moreover, Stiglitz maintains that tax avoidance is easy for the rich, which translates in practice to lower tax rates vis-à-vis the rates applied to workers, weakening in turn the tax revenue needed by the government to stimulate the economy. Krugman objects to this last point, too; he argues that although tax avoidance is easier for the rich, they do end up paying more. Still, he misses the point of the overall argument, again, because he places the emphasis on personal income taxation. When dynasties of the wealthy are considered, the effective tax rate on the dynasty, say on the father and heir(s) lumped as one person, will typically be less than the rate applied to each dynasty member separately. For example, a father and an heir may be found paying $\$ 200$ each, but if they were taxed as a single person the tax revenue from them might have been $\$ 450$, because of the progressiveness of the tax schedule. It is not the arithmetic per se that matters for such a counterargument to Krugman's objection; it is that this arithmetic has been documented to be a major source of wealth inequality [2]. Of course, an empirical investigation of the assertions made here numerically is needed, but this lies beyond the scope of this note.

Rather, the purpose here is to obtain a glimpse of the big picture of the national and international economic trends; to this end, once Stiglitz's conclusions have been clarified, they will be related to the environment in which they have been observed. It is the environment of globalization on which Minsky [4] reports: "due to "financialization of the real economy", the picture is... one of... an investment-starved real economy, one where the real economy itself has retreated from funding investment opportunities and is instead either hoarding cash or using corporate profits for speculative investments..." That is, the wealth owners behind businesses prefer to invest in the 
domestic and international financial markets and to lend to their workers instead of paying them higher wages, because it is simply more profitable to do so. Of course, it would be difficult to exploit international financial markets outside the context of globalization. One is thus inclined to conclude that wealth owners exploit the technological progress-induced trend for higher integration of the world economy so as to increase the profitability of their funds. They do so, favoring financial over real economy activities, which in turn weakens the socioeconomic status of labor. The need for labor's collaboration with the employer for the success of a production plan has become minimal, and the purchasing power of labor has been hurt seriously because the employer has turned from an entrepreneur to a gambler in the financial markets. What the international economy is experiencing today is under-consumption, not exactly because of over-production, as suggested by Hobson, or because of over-production plus maldistribution of income as suggested by Sismondi, but because of under-production plus maldistribution of income prompted by the neo-imperialism of globalization. Say's law is operative from this point of view. This is what logically may be inferred from what the theories of Stiglitz-cum-Minsky. Over-production is inherent to financial globalization and has been manifested through the proneness of the system to recession [9].

\section{Policy Considerations}

In any case, what the government should do is clear enough: regulate the financial system and industry, and stimulate the economy through fiscal and monetary policies as follows. The current focus of central banking on commercial bank insolvency works against the traditional separation of retail from investment banking, strengthening resource misallocation in favor of the banks; to solve this, banking should return back to tradition [10]. Also, better corporate governance and anti-trust laws as well as stronger workers' rights should be pursued. The option of expanding the institution of Employee Stock Ownership Plan (ESOP, worker cooperatives) should be examined seriously as well, since, as Kruse [11] reports to the Committee on Education and the Workforce of the U.S. House of Representatives, "productivity improves by an extra $4-5 \%$ on average in the year an ESOP is adopted," and remains high in subsequent years. Next, insofar as fiscal policy is concerned, it should expand the provision of public goods, and see that taxes and transfers are genuinely progressive in order to alleviate inequality in before- and after-tax as well as in transfer distribution of income. Finally, an expansionary helicopter-money monetary policy, a sort of quantitative easing aimed at strengthening consumer purchasing power directly without bank intervention, might also be useful. This is Friedman's [12] sense of helicopter money, which is not meant to be money issuance to cover fiscal expenses. Yet, it might be used to fight under-consumption either in conjunction with fiscal policy or alone.

In a few words, there is no shortage of policy means against the undesirable consequences of inequality. Yet, they are means deliberated at the national economy level and their success depends on the extent of the control of the economy by its government. Globalization, which is one major development responsible for the increasing inequality, has at the same time been reducing the scope and effectiveness of national policymaking. Free trade, capital market liberalization, and business outsourcing have considerably weakened national sovereignty insofar as a national government's ability to exercise domestic economic policymaking is concerned. Although this appears to be a "natural" consequence of any sort of globalization, the inequality increasing within and across countries is specific only to the institutional background surrounding the current form of globalization. The next section provides an example suggesting that the weakening of the nation-state is not at all a "natural" consequence of any type of globalization, but rather is positively related to increasing inequality. The positive correlation between the increasing inequality and weakening nation-state is plain to see in daily news. It is a vicious circle, with the rising inequality progressively reducing the effectiveness of domestic policymaking, and vice versa.

In general, policy measures with an international perspective have to be designed and implemented. For instance, one such measure is Tobin's tax regarding sizeable international financial 
transactions, full-reserve banking across the board, and a revision of the content of property rights on inheritance. This is a policy of international coordination. The next section presents a theoretical example of a redistributive policy based on international indirect tax competition. It is a policy proposal construed in the realm of "some" international fiscal federalism, so to speak. Globalization has been weakening efficiency at the subnational government level [13]. Yet, to the extent that there can be "functional autonomy for efficiency gain and competition and to attract private capital" (p. 41) at the national level, it appears that there can also be scope for international intergovernmental fiscal competition, as follows.

\section{A Discussion of Fiscal Globalism}

Could fiscal globalism, that is, national competition to attract and retain global capital in a fiscal federalism fashion, be used to redistribute wealth away from the wealthy that are behind multinational corporations? What should the stance of a local government towards its constituency and other governments be to attain this target? To investigate such a possibility, let a central global fiscal authority contemplating the imposition of an excise tax, $T$, on the market demand for a good $Q$, as follows:

$$
Q=a-b(P+T)
$$

where $P$ is the price of this good, and a and $\mathrm{b}$ are some positive constants such that $a>b(P+T)$. Good $\mathrm{Q}$ is produced by a monopoly in two jurisdictions, 1 and 2, according to shares, $Q_{i}=s_{i} Q, s_{i}+s_{j}=1$, $i, j=1,2 . i \neq j$, under identical cost conditions, and are not subject to any local taxes. Hence, solving Equation (1) for $P$ :

$$
P=(a-Q-b T) / b
$$

profit is:

$$
\Pi=[(a-Q-b T) Q / b]-\vartheta Q^{2}+\zeta Q
$$

where $C=\vartheta Q^{2}-\zeta Q$ is the production cost. The consumers of $Q$ across the two jurisdictions are identical and, given Equation (2), utility is calculated by integrability:

$$
U=\left(2 a Q-Q^{2}-b Q T\right) / 2 b
$$

The presence of socioeconomic stratification implies that the consumer under this model is the average consumer of the median voter theory. The tax authority has three options, namely, to impose $T$ either to maximize only its tax revenue, $R=Q T$, or to maximize this revenue plus consumer surplus, $C S=U-P$, or to maximize in addition to producer surplus, $P S$, which is the profit margin. Disregarding surpluses, that is, maximizing only $R$ with respect to $T$, it is easily shown, as in Reference [14], that the optimal tax would be:

$$
\bar{T}=\frac{a-b P}{2 b}
$$

Let us compare this tax with those emerging from the other two cases. Suppose, first, that the objective of the central tax authority is to impose the excise tax so as to maximize tax revenue and consumer surplus, for which the sum is in view of Equations (1), (2), and (4):

$$
R+C S=\frac{\left(a^{2}-2 b P-b^{2} P^{2}\right)+(a-2 b P) b T-2 b^{2} T^{2}}{2 b}
$$

Setting the derivative of Equation (6) with $T$ equal to zero and solving for $T$, one obtains:

$$
T=\frac{a-2 b P}{4 b}>0 \Rightarrow
$$


where $a>3 b P$. This is the optimal tax regardless how the production of $Q$ is distributed between the two jurisdictions. It is smaller than $\bar{T}$ because $T<\bar{T} \Rightarrow 1<2$, which is true. Suppose next that the objective of tax administration is to maximize Equation (6) plus PS, as given by Equation (3), which in view of Equation (1) becomes:

$$
\Pi=\Phi+\Psi T-\vartheta b^{2} T^{2}
$$

where $\Phi=\left(a \zeta+a P-b \zeta P-b P^{2}-\vartheta a^{2}-\vartheta b^{2} P^{2}+2 \vartheta a b P\right)$ and $\Psi=b(2 \vartheta a-\zeta-P-2 \vartheta b P)$. The derivative:

$$
\frac{\partial \Pi}{\partial T}=b(2 \vartheta a-\zeta-P-2 \vartheta b P-2 \vartheta b T)<0
$$

because from Equation (1), $a=Q+b(P+T)$, which when inserted in the parenthesis, gives:

$$
2 \vartheta Q+2 \vartheta b P+2 \vartheta b T-\zeta-P-2 \vartheta b P-2 \vartheta b T=(2 \vartheta Q-\zeta)-P<0
$$

since $(2 \vartheta Q-\zeta)$ is the marginal cost $(\mathrm{MC})$, under imperfect competition MC is less than the price. So, the optimal tax now becomes:

$$
T^{*}=\frac{(a-2 b P)-2[P-(2 \vartheta Q-\zeta)]}{4 b(1+\vartheta b)}
$$

Certainly, $T^{*}>0 \Leftrightarrow(a-2 b P)-2[P-(2 \vartheta Q-\zeta)]>0$. And, clearly:

$$
T^{*}<T \Rightarrow-2[P-(2 \vartheta Q-\zeta)]<\vartheta b(a-2 b P)
$$

which is true. In sum, $T^{*}<T<\bar{T}$. That is, the more the central global fiscal authority is minded about satisfying strong Pareto efficiency, the less tax revenue it has to collect worldwide. Of course, the optimal level of global public services, $G$, that should be provided is $G=T^{*}$. Nevertheless, if the global fiscal authority had in mind the attainment of weak Pareto efficiency, collecting $\bar{T}$, spending $G=T^{*}$, and redistributing $\bar{T}-T^{*}$ to alleviate national and international inequality, the only principle that should be dictating its behavior should be its own interest as a tax collection administration regardless the opinion(s) of the national governments and their constituencies.

Now, let us introduce into the analysis the role that two national jurisdictions play with regard to optimal taxation. They may impose their own unit taxes as well, $t_{i}$ and $t_{j}$, so as to raise the share of $Q$ produced in their boundaries. Let the two localities be competing in a Cournot fashion, so that:

$$
R_{i}=s_{i} Q t_{i}=s_{i}\left[a-b\left(P+t_{i}+t_{j}\right)\right] t_{i}
$$

which implies that:

$$
\bar{t}_{i}=\frac{a-b P}{3 b}
$$

It is noteworthy that the share coefficient, $s_{i}$, does not influence the tax rate, therefore:

$$
\bar{t}_{1}+\bar{t}_{2}=\frac{2(a-b P)}{3 b}>\bar{T} \Rightarrow
$$

where $a>b P$, which is true. That is, if the target is tax revenue maximization and the Laffer curve peaks at $\bar{T}$, the two localities tax jointly beyond that peak. However, if each jurisdiction aims at CS maximization as well, based on:

$$
R_{i}+C S=\left[a-b\left(P+t_{i}+t_{j}\right)\right] t_{i}+\frac{a^{2}-2 b P-b^{2} P^{2}-a b\left(t_{i}+t_{j}\right)}{2 b}
$$

the resulting total is:

$$
t_{1}+t_{2}=\frac{a-2 b P}{3 b}>T \Rightarrow
$$


where $4>3$, which is true. However, note that:

$$
\bar{T}>t_{1}+t_{2} \Rightarrow a>-b P
$$

which is also true. Finally, accounting for PS as well:

$$
t_{1}^{*}+t_{2}^{*}=\frac{4(1+\vartheta b)\{a-2 \zeta b+4 b[\vartheta(a-b)-P(1+\vartheta b)]\}}{(1+2 \vartheta b)(3+2 \vartheta b)}
$$

and as it is shown in the Appendix A:

$$
T^{*}>t_{1}^{*}+t_{2}^{*}
$$

In sum, $t_{1}^{*}+t_{2}^{*}<T^{*}<T<t_{1}+t_{2}<\bar{T}<\bar{t}_{1}+\bar{t}_{2}$. The overall conclusion is that local national governments can address the matter of inequality more effectively than a central global tax authority could. This ranking of taxes holds given the same demand for $Q$, because if $\Delta$ is the change operator and $\tau$ denotes any of these taxes:

$$
\begin{gathered}
\Delta R=Q \Delta \tau+\tau \Delta Q=[a-b(P+\tau)] \Delta \tau+\tau \Delta[a-b(P+\tau)] \Rightarrow \\
\Delta R=a \Delta \tau-b P \Delta \tau-2 b \tau \Delta \tau-b \tau \Delta P \Rightarrow \\
\frac{\Delta R}{\Delta \tau}=a-b P-2 b \tau-b \tau \frac{\Delta P}{\Delta \tau}=a-b P-b \tau=Q \Rightarrow \\
\Delta R=Q \Delta \tau
\end{gathered}
$$

Hence, the term $\tau \Delta Q=0 \Rightarrow \Delta Q=0$. That is, local and global demand for the goods and services supplied by multinational companies is influenced neither by the identity of the tax authority nor by the kind of Pareto-efficiency mentality underlying the tax authority. In addition, and more importantly, demand is not influenced by the presence of tax, pointing to a full shift of the tax burden to the consumer and an unchanged supply of goods and services; the tax does not influence the course of economic activity neither nationally nor internationally. To reach an overall conclusion from the above calculus, recall that the consumer contemplated is the average consumer of median voter theory. Consequently, what income redistribution does is to compensate for the tax burden shifted to the average consumer. In other words, it prevents the rich from becoming richer; this can be achieved more effectively by a national rather than global government. It is the national government whose focus should be the competition with the other national governments, rather than the satisfaction of its constituency.

\section{Conclusions}

The rising factor of income inequality of our times, having started in the 1980s, attracted policy attention in the 1990s [8], and nowadays having reached extreme proportions [2], has been held responsible for the under-consumption and subsequent stagnancy in the US and world economies. This article presented the crux of the under-consumption argument and linked it to the under-production accompanying modern financial globalization, thus arriving at a Say's law interpretation of the current state of national and world economies. It next discussed the ensuing policy recommendations, speculating on whether some sort of international tax competition to attract and retail capital locally can be useful as a means of halting the increase of inequality. Hypotheses rejecting the under-consumption thesis on the basis of an interpretation of Say's law, according to which the system does not leave businessmen free to supply the goods and services needed to create the demand which is indispensable to growth, are naive. Such viewpoints would be true if businesses did want to invest in productive capacity, having thereby to reward labor properly in order to make it an ally to its plans. However, the Stigliz-Minsky analysis above suggests that the wealth owners 
behind businesses think otherwise, given a system which underrates investment yield relative to financial capital profit.

This is not in line with Say's law; it is in line with the Marxian "accumulation for accumulation's sake" of Aristotelian unproductive speculative funds, of money-making money. At the international front, the same people who point to "their version" of Say's law maintain that the reason there are countries suffering from globalization is their inward-looking domestic policies. They neglect the fact that these are the same countries with higher foreign direct investment, hushing up the overall conclusion that globalization cannot deliver to them the slightest growth, let alone development. All in all, the theses of such proponents of Say's law would make an activist exclaim "down with the system" instead of "down with the institutions that twist the system." At the other end, the system manifests neither the Marxian over-production nor the Keynesian insufficient demand to justify statism as a remedy. If the declining pre-globalization top $1 \%$ income is seen as verifying Marx's law of declining profit rate, the increasing top $1 \%$ income once globalization was launched suggests that the pro-financial sector bias of globalization has been the result of efforts to reverse the declining profit rate. Perhaps this is so, but the current state of the national and international economies is far from being one of over-production. Moreover, as explained earlier, modern under-consumption is the outcome of under-production and not the opposite; hence, it cannot be identified with Keynesian insufficient demand.

Modern under-consumption does refer to the lack of effective demand for products that would justify a reinvestment in new plants. However, it is the unwillingness to undertake such investments that has caused the insufficient demand in the first place; financial investment pays better. For Keynes, an economy such as modern globalization, encouraging the love for money, would be unthinkable: "love of money (as) a somewhat disgusting morbidity, one of the semi-criminal, semi-pathological propensities which one hands over with a shudder to specialists in mental disease" [15]. Yet, a "greedy globalization" has actually come up and is subject to internal contradictions as, of course, would have been anticipated by Marx. International economic integration has been progressing under the impulse of the decentralized market system. The money made by some elite under this system might as well become thin air tomorrow if the system continues to operate uninhibited. A central world authority to regulate markets against this eventuality is what these money elite should be pursuing. It should also be an authority that will be stirring the further development of globalization in line with these elite interests, which cannot be done if nation states compete with the elite. Still, this scheme is self-destructive, as evidenced by the earlier analysis, unless the centralization pursued by the elite is replaced by the decentralization of competing nation states. According to this article, the competition of nation states in a fiscal globalism fashion crystallizes the optimal level of centralization under globalism; optimal, that is, from the viewpoint of safeguarding against the manipulation of world markets by financiers.

Acknowledgments: This article has benefited from the constructive suggestions of the editors and two anonymous reviewers. Any remaining errors and/or omissions are the author's.

Conflicts of Interest: The author declares no conflict of interest.

\section{Appendix}

We aim to show that:

$$
T^{*}>t_{1}^{*}+t_{2}^{*} \Rightarrow \frac{T^{*}(1+2 \vartheta b)(3+2 \vartheta b)+8 b(1+\vartheta b)(\zeta+\vartheta b)+8 b P(1+\vartheta b)^{2}}{4(1+\vartheta b)(1+2 \vartheta b)}>a
$$

If:

$$
\frac{T^{*}(3+2 \vartheta b)+8 b(\zeta+\vartheta b)+8 b P(1+\vartheta b)}{4(1+2 \vartheta b)}>a
$$


is true, (A1) will also be true because $T^{*}$ on (A1) is multiplied with the positive term $(1+2 \vartheta b)$ too, and hence the numerator of (A1) is greater than the numerator of (A2). Next, note that:

$$
\frac{T^{*}(3+2 \vartheta b)+8 b(\zeta+\vartheta b)+8 b P(1+\vartheta b)}{4(1+2 \vartheta b)}-b P>a-b P
$$

where the right-hand side of this inequality is the before-tax $Q$ :

$$
\frac{T^{*}(3+2 \vartheta b)+8 b(\zeta+\vartheta b)+8 b P(1+\vartheta b)}{4(1+2 \vartheta b)}-b P>Q
$$

Since this $Q$ is:

$$
Q=\frac{a+b \zeta}{2(1+\vartheta b)} \Rightarrow 2(1+\vartheta b)=\frac{a+b \zeta}{Q}
$$

(A3) may be rewritten as follows:

$$
\begin{gathered}
\frac{T^{*}(3+2 \vartheta b) Q+8 b(\zeta+\vartheta b) Q+4 b P(a+b \zeta)}{4(1+2 \vartheta b) Q}>Q \Rightarrow \\
\frac{T^{*}(3+2 \vartheta b) Q+8 b(\zeta+\vartheta b) Q+4 b P(a+b \zeta)}{4(1+2 \vartheta b) Q}-Q>0 \Rightarrow \\
4(1+2 \vartheta b) Q^{2}-\left[T^{*}(3+2 \vartheta b)+8 b(\zeta+\vartheta b)\right] Q-4 b P(a+b \zeta)<0
\end{gathered}
$$

Solving the left-hand side of $\left(\mathrm{A}^{\prime}\right)$ for $Q$, gives the two roots:

$$
\begin{gathered}
Q_{1,2}=\frac{-\left[T^{*}(3+2 \vartheta b)+8 b(\zeta+\vartheta b)\right]}{8(1+2 \vartheta b)} \pm \\
\pm \frac{\sqrt{\left[T^{*}(3+2 \vartheta b)+8 b(\zeta+\vartheta b)\right]^{2}+64 b(1+2 \vartheta b) P(a+b \zeta)}}{8(1+2 \vartheta b)}
\end{gathered}
$$

The root with the negative sign of the discriminant is negative and hence, $Q$ should be even "more negative" under $\left(\mathrm{A}^{\prime}{ }^{\prime}\right)$. For the root with the positive sign of the discriminant, it would be positive if:

$$
\begin{aligned}
{\left[T^{*}(3+2 \vartheta b)+8 b(\zeta+\vartheta b)\right]^{2}>} & {\left[T^{*}(3+2 \vartheta b)+8 b(\zeta+\vartheta b)\right]^{2}+64 b(1+2 \vartheta b) P(a+b \zeta) \Rightarrow } \\
& 0>64 b(1+2 \vartheta b) P(a+b \zeta)
\end{aligned}
$$

which is not true. What is true for root $Q_{i}$ is also true for $Q_{j}, i=1,2, i \neq j$. Therefore, (A3) and thereby (A2) and (A1) are true.

Consumer surplus will be under $T^{*}$ :

$$
\begin{gathered}
C S^{*}=\frac{3 a^{2}-8 b P+2 a b P-4 b^{2} P^{2}}{8 b}>0 \Rightarrow \\
3 a^{2}>8 b P+4 b^{2} P^{2}-2 a b P
\end{gathered}
$$

while in the absence of $T$ :

$$
\begin{gathered}
C S_{T=0}=\frac{a^{2}-2 b P-b^{2} P^{2}}{2 b}>0 \Rightarrow \\
a^{2}>2 b P+b^{2} P^{2}
\end{gathered}
$$

We have to show that (A5) and (A7) are true. The inequality, $C S_{T=0}>C S^{*}$, reduces to $3 b^{2} P^{2}+6 b P-2 a b P+a^{2}>3 a^{2}$, which, if true, then in view of (A5), $3 b^{2} P^{2}+6 b P-2 a b P+a^{2}>8 b P+4 b^{2} P^{2}-2 a b P \Rightarrow a^{2}>2 b P+b^{2} P^{2}$, which is what (A7) maintains. That is, (A5) and (A7) hold if $C S_{T=0}>C S^{*}$, or the opposite, (A5) and (A7) ensure that $C S_{T=0}>C S^{*}$. Moreover, note that: 


$$
\hat{C S}=\frac{a^{2}-4 b P+a b P-2 b^{2} P^{2}}{4 b}
$$

with $C S^{*}>\hat{C S} \Rightarrow a^{2}>0$, which is true.

\section{References}

1. The Economist. War, Plague, Capital Flows and Factories: Is Inequality Here to Stay? 1 April 2017. Available online: http:/ /www.economist.com/blogs/buttonwood/2017/04/war-plague-capital-flows-and-factories (accessed on 1 April 2017).

2. Pikkety, T.; Saez, E. Inequality in the Long Run. Science 2014, 344, 838-843. [CrossRef] [PubMed]

3. Stiglitz, J.E. Inequality is holding back the recovery. The New York Times. 19 January 2013. Available online: https:/ /opinionator.blogs.nytimes.com/2013/01/19/inequality-is-holding-back-the-recovery/ (accessed on 19 January 2013).

4. Mazzucato, M.; Wray, L.R. Financing the Capital Development of the Economy: A Keynes-SchumpeterMinsky Synthesis. Available online: http://dx.doi.org/10.2139/ssrn.2603847 (accessed on 9 May 2015).

5. Sismondi, S. Nouveaux Principes D'économie Politique, ou de la Richesse Dans ses Rapports Avec la Population; Paris, Delauney: Paris, France, 1819.

6. Mummery, A.F.; Hobson, J.A. The Physiology of Industry: Being an Exposure of Certain Fallacies in Existing Theories in Economics; John Murray: London, UK.

7. Foster, J.B. The New Imperialism of Globalized Monopoly-Finance Capital: An Introduction. Mon. Rev. 2015, 67, 1-22. [CrossRef]

8. Krugman, P. Inequality and recovery. The New York Times. 20 January 2013. Available online: https:/ / krugman.blogs.nytimes.com/2013/01/20/inequality-and-recovery/ (accessed on 20 January 2013).

9. Manera, C. A Systemic Crisis in the Context of Globalization: The Great Recession in the Perspective of Economic History, 1970-2008; University of the Balearic Islands: Palma, Spain.

10. Dow, S.; Johnsen, G.; Montagnoli, A. A Critique of Full Reserve Banking, 2015; Sheffield Economic Research Paper Series; Department of Economics, University of Sheffield: Sheffield, UK, 2015.

11. Kruse, D. Research Evidence on Prevalence and Effects of Employee Ownership. Available online: https://www.ownershipassociates.com/kruse.shtm (accessed on 13 February 2002).

12. Friedman, M. The Optimum Quantity of Money; Aldine Publishing Co.: Chicago, IL, USA, 1969.

13. Bagchi, A. Globalisation and Federalism: Uneasy Partners? Econ. Political Wkly. 2008, 43, 41-48.

14. Shughart, W.F., II; Tollison, R.D. Fiscal Federalism and the Laffer Curve. J. Public Financ. Public Choice 1991, 514, 21-28.

15. Keynes, J.M. Economic Possibilities for Our Grandchildren. In Essays in Persuasion; W.W. Norton \& Co.: New York, NY, USA, 1963; pp. 358-373.

(C) 2017 by the author. Licensee MDPI, Basel, Switzerland. This article is an open access article distributed under the terms and conditions of the Creative Commons Attribution (CC BY) license (http:/ / creativecommons.org/licenses/by/4.0/). 